\title{
Changes in hepatic superoxide dismutase and xanthine oxidase activity in mice infected with Salmonella typhimurium and Pseudomonas aeruginosa
}

\author{
MEGUMI TAKAHASHI, TSUTOMU USHIJIMA and YOSHIKATSU OZAKI \\ Department of Microbiology, Shiga University of Medical Science, Otsu, Shiga, 520-21, Japan
}

\begin{abstract}
Summary. Liver xanthine oxidase (XOD) and superoxide dismutase (SOD) activities were compared in mice during Salmonella typhimurium and Pseudomonas aeruginosa infections. We observed that XOD activity rose but SOD activity fell for the first 11 days after infection with smooth type $S$. typhimurium, coinciding with the period of bacterial growth in the liver. Rough type $S$. typhimurium did not establish an infection and mice inoculated with this strain showed no variation in enzyme activities. $P$. aeruginosa infection was mild but stimulated both XOD and SOD activities.
\end{abstract}

\section{Introduction}

Xanthine oxidase (XOD) is distributed widely among mammalian species and is found within various tissues (Jarasch et al., 1981). It exists in vivo predominantly as a dehydrogenase which can be transformed to an oxygen-dependent oxidase by various conditions (Kaminski and Jeżewska, 1979). Although the main physiological function of XOD is unclear, there is growing interest in the potential of this enzyme to serve as a source of oxidising agents such as the superoxide radical and $\mathrm{H}_{2} \mathrm{O}_{2}$ (Chambers et al., 1985). Superoxide dismutase (SOD) is another enzyme widely distributed in various tissues, but it can be found particularly in the liver. It catalyses the initiation of the superoxide radical, presumably generated in these tissues by XOD, thus relieving the toxic effect of superoxide. Tubaro et al. (1980a) found a significant increase in liver XOD activity in mice infected with bacteria, thereby supporting the concept that natural defence mechanisms involve XOD. We compared the activities of these two enzymes (SOD and XOD), which are involved in superoxide metabolism and are localised particularly in the soluble fraction of liver homogenate, using livers from mice infected with Salmonella typhimurium (smooth and rough types) and Pseudomonas aeruginosa.

\section{Materials and methods}

Outbred female ICR mice, 5-6 weeks old, were given smooth type $S$. typhimurium LT-2 $2.9 \times 10^{3} \mathrm{cfu} /$ mouse

Received 17 Nov. 1987; accepted 11 Jan. 1988.
(0.1 LD50), rough type $S$. typhimurium SL-1181 1.0 $\times 10^{6}$ cfu/mouse (0.1 LD50), or $P$. aeruginosa ATCC 27853 $1.1 \times 10^{6} \mathrm{cfu} /$ mouse $(0.1$ LD50) by intraperitoneal (i.p.) injection. Three infected and three control animals were killed at various intervals after i.p. inoculation. The liver and spleen of each mouse were excised and rinsed in phosphate-buffered saline (PBS), weighed, and homogenised with a glass-Teflon homogeniser in $0.05 \mathrm{M} \mathrm{KCl}$. The homogenates were appropriately diluted and plated on to Heart Infusion Agar (Nissui Co. Ltd). After incubation at $37^{\circ} \mathrm{C}$ for $24 \mathrm{~h}$, the number of colonies was counted. A sample of liver homogenate was centrifuged at 10000 $\mathrm{rpm}$ for $15 \mathrm{~min}$ at $4^{\circ} \mathrm{C}$ and the supernate was kept on ice and assayed for SOD and XOD. The SOD activity was assayed by the method of Beauchamp and Fridovich (1971). The reaction mixture contained $0.1 \mathrm{mM}$ xanthine, $0.025 \mathrm{~mm}$ nitroblue tetrazolium (NBT), $0.1 \mathrm{mM}$ EDTA, $0.06 \mathrm{M}$ sodium carbonate buffer $(\mathrm{pH} \mathrm{10.2)}$, and xanthine oxidase. The rate of reduction of NBT was measured at $560 \mathrm{~nm}$. One unit of SOD was defined as the amount of enzyme that inhibited $50 \%$ of the rate of NBT reduction at room temperature. XOD activity was determined by spectrophotometric measurement of uric acid formation at $290 \mathrm{~nm}$ (Affonso et al., 1981). The reaction mixture contained $0.015 \mathrm{M}$ pyrophosphate buffer (pH 8.6) and $2 \times$ $10^{-3} \mathrm{M}$ hypoxanthine. Protein concentration in the crude homogenate was assayed by the biuret reaction.

\section{Results}

Comparison of the bacterial growth in liver and spleen

The number of bacteria in both organs of mice infected with $S$. typhimurium LT-2 gradually increased and reached a maximum level 6 days after infection; there was then a gradual decrease. Only a few bacteria were detected in mice infected with 
$P$. aeruginosa one day after the induced infection, and no bacteria were detected in mice infected with $S$. typhimurium SL-1181 during the entire observation period (fig. 1).

\section{Comparison of SOD activity in the liver}

From three to nine days after infection with $S$. typhimurium LT-2, SOD activity was significantly reduced to about $50 \%$ of that in the control mice. At 11 days, activity reverted to the same level as that in the controls. Conversely, in mice given $S$. typhimurium SL-1181, SOD activity remained at the same level as in the control mice. In mice infected with $P$. aeruginosa, the maximum SOD activation (about a two-fold increase) occurred 3 days after infection and decreased progressively to the normal level during the following 2 days (fig. 2).

\section{Comparison of $X O D$ activity in the liver}

From 3 to 7 days after infection with $S$. typhimurium LT-2, the XOD activity gradually increased, reached a maximum (about six-fold increase) on day 11 and remained at a relatively high level during subsequent days. In the case of $S$.

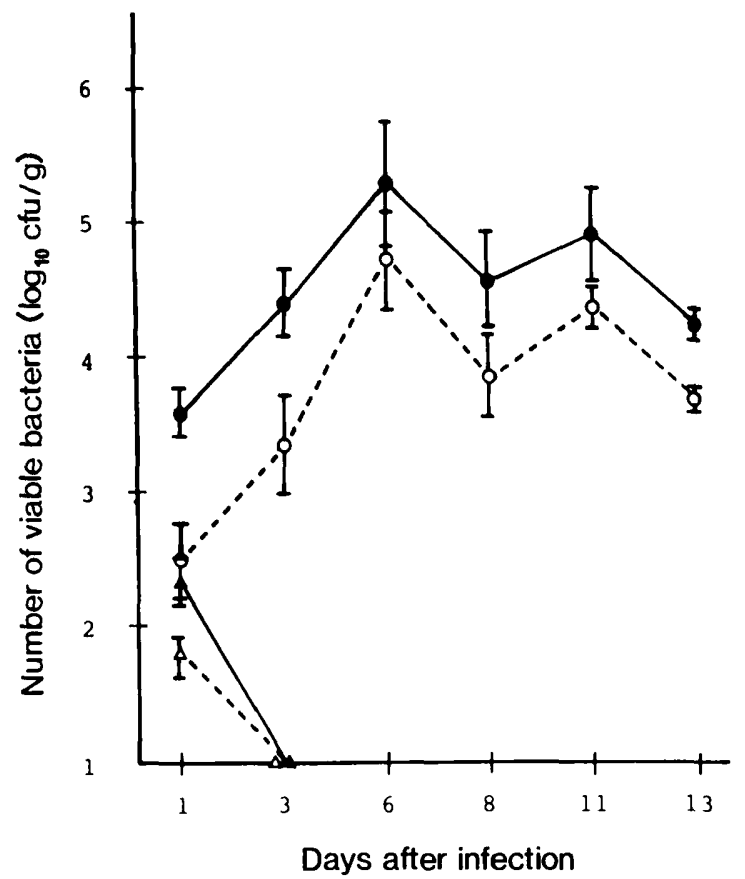

Fig. 1. Mean counts (cfu/g) of viable $S$. typhimurium LT-2 (O, $O)$, and $P$. aeruginosa $(\triangle, \Delta)$ in the liver $(O, \triangle)$ and spleen $(\mathcal{A}, \Delta)$. S. typhimurium SL-1181 was not detected in either tissue. Each point and bar indicates the mean count for three mice $\pm \mathrm{SD}$.
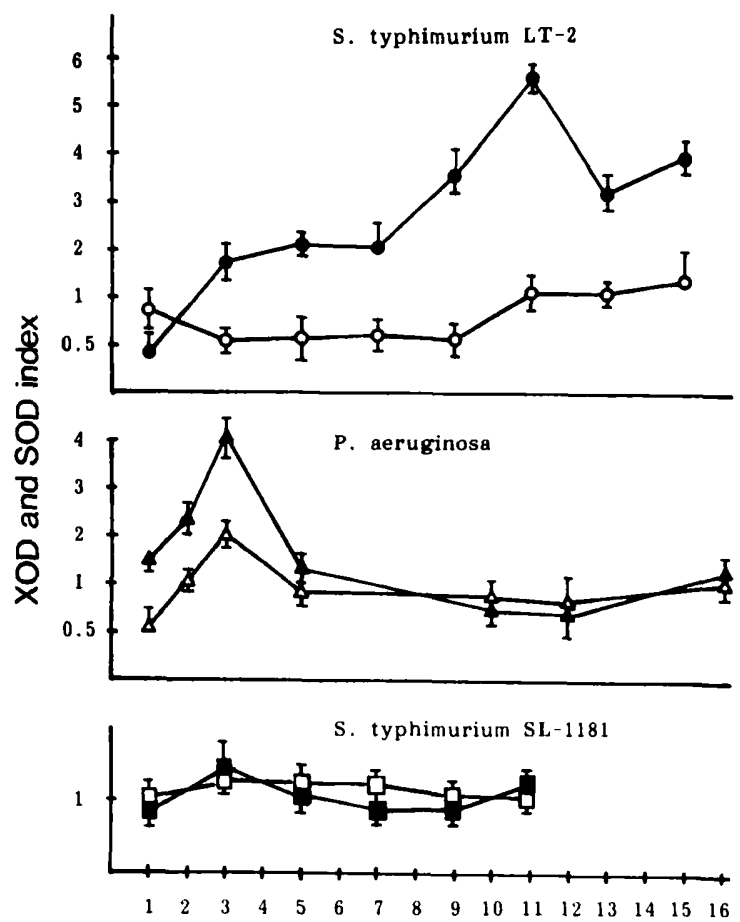

Days after infection

Fig. 2. Changes in $\operatorname{SOD}(O, \square, \triangle)$ and $\operatorname{XOD}(O, \square, \Delta)$ activities in the liver after $S$. typhimurium LT-2 $(\mathcal{O}, O), S$. typhimurium SL-1181 ( $\square, \square)$ or $P$. aeruginosa $(\Lambda, \triangle)$ infection. Each point and bar indicates the mean activity for three mice \pm SE.

SOD Index $=\frac{\text { SOD activity (units } / \mathrm{mg} \text { of protein) in infected mice }}{\text { SOD activity (units } / \mathrm{mg} \text { of protein) in control mice }}$

$\mathrm{XOD}$ Index $=\frac{\mathrm{XOD} \text { activity }(\mathrm{nmol} / \mathrm{mg} \text { of protein } / \mathrm{min}) \text { in infected mice }}{\mathrm{XOD} \text { activity }(\mathrm{nmol} / \mathrm{mg} \text { of protein } / \mathrm{min}) \text { in control mice }}$

typhimurium SL-1181, XOD activity was not significantly altered and remained at the same level as in the control mice. In mice infected with $P$. aeruginosa, maximum XOD activation (about four-fold increase) occurred 3 days after the infection and decreased progressively to the normal level during the following 2 days (fig. 2).

\section{Discussion}

Treatment of mice with interferon or an interferon-inducer, such as poly-I.C., enhances liver XOD activity. Such enhancement may be responsible for the various biological activities of interferon, including increased resistance to bacterial infection in mice and enhanced activity of natural killer cells and monocytes (Ghezzi et al., 1984). Augmentation of XOD induced by interferon enhances lipid peroxidation, resulting in a decrease 
in function of the cytochrome P-450 system (Deloria et al., 1985; Koizumi et al., 1986). On the other hand, it was reported that liver SOD activities are reduced in mice infected with Plasmodium berghei or in tumour bearing mice (Kulkarni et al., 1981; Leuthauser et al., 1984). Since SOD functions to catalyse the inactivation of the superoxide radical, a reduction in SOD activity may result in elevation of the levels of oxygen intermediates and eventually lead to increases in lipid peroxidation in the liver. Thus, increased levels of oxygen intermediates by either enhancement of XOD activity or depression of SOD activity have biological consequences. These include both beneficial effects in the form of microbicidal activity and untoward effects in the form of serious damage to physiological systems.

Tubaro et al. (1980b) found a significant increase in liver XOD activity in mice infected with Staphylococcus aureus and proposed that NADPH oxidase is not the major source of superoxide generated by phagocytes. Stimulation of XOD activity seemed to be responsible for the flux of superoxide. We observed the influence of different bacterial infections, with both intracellular and extracellular parasites, on XOD and SOD activity. After injection of $S$. typhimurium LT-2 into mice, there was an increase in the numbers of bacteria in the liver and spleen. In the first period of infection, XOD activity gradually increased while SOD activity remained at a low level, compared with levels in control mice. Changes in both enzyme activities generally correlated with growth of $S$. typhimurium LT-2 in the organs. However, there was a significant increase in XOD levels between 7 and 11 days, while bacterial numbers showed a slight decrease. In the case of $P$. aeruginosa, only small numbers of bacteria were recovered from the liver one day after infection and XOD activity increased temporarily in the early phase of infection, a finding coinciding with the activation of SOD. S. typhimurium SL-1181 was not detected in either organ during the observation period and both enzyme activities remained at the same levels as in the control mice. These data suggest that increase in oxygen intermediates following activation of XOD played a role as potent bactericidal agents during the multiplication of bacteria. But in comparison with the elevation of XOD activity, bacterial numbers in mice infected with $S$. typhimurium LT-2 decreased gradually in the late phase of infection. There seem to be differences in susceptibility to oxygen intermediates among bacterial species which may relate to virulence. As a high level of glutamate pyruvate transaminase (GPT) activity in serum from mice infected with $S$. typhimurium LT-2 was observed (data not shown), damage to liver tissues was considered to be caused not only by bacteria but also by oxygen intermediates. SOD activity decreased slightly when the XOD activity showed a tendency toward a gradual increase. In contrast, SOD activity increased gradually when XOD activity showed a rapid rise. Such a concomitant relationship between SOD and XOD activities in the liver of mice infected with pathogenic bacteria may reveal a defence mechanism in the host to exclude pathogens without significant tissue damage by oxygen intermediates.

\section{REFERENCES}

Affonso O R, Moura C V A, Cavallari V, Mitidieri E 1981 Serum and liver xanthine oxidase activity in tumor bearing rats and mice. Anais Da Academia Brasileira De Ciencias 53: $617-620$

Beauchamp C, Fridovich I 1971 Superoxide dismutase: improved assays and an assay applicable to acrylamide gels. Analytical Biochemistry 44: 276-287.

Chambers D E, Parks D A, Patterson G, Roy R, McCord J M, Yoshida S, Parmley L F, Downey J M 1985 Xanthine oxidase as a source of free radical damage in myocardial ischemia. Journal of Molecular and Cellular Cardiology 17: $145-152$.

Deloria L, Abbott V, Gooderham N, Mannering G J 1985

Induction of xanthine oxidase and depression of cytochrome P-450 by interferon inducers: genetic difference in the response of mice. Biochemical and Biophysical Research Communications 131 : 109-114.

Ghezzi P, Bianchi M, Mantovani A, Spreafico F, Salmona M 1984 Enhanced xanthine oxidase activity in mice treated with interferon and interferon inducers. Biochemical and Biophysical Research Communications 119: 144-149.

Jarasch E D, Grund C, Bruder G, Heid H W, Keenan T W, Franke W W 1981 Localization of xanthine oxidase in mammary-gland epithelium and capillary endothelium. Cell 25 : 67-82.

Kaminski Z W, Jezewska M M 1979 Intermediate dehydrogenase-oxidase form of xanthine oxidoreductase in rat liver. Biochemical Journal 181 : 177-182. 
Koizumi A, Walford R L, Imamura T 1986 Treatment with poly I.C. enhances lipid peroxidation and the activity of xanthine oxidase, and decreases hepatic P-450 content and activities in mice and rats. Biochemical and Biophysical Research Communications 134: 632-637.

Kulkarni A B, Ved H S, Ramarkrishman P, Pradhan V R, Renapurkar D M, Sharma K D 1981 Studies on superoxide dismutase and catalase in different tissues of rat infected with Plasmodium berghei. Bulletin Haffkine Institute 9 : 29 33.

Leuthauser S W C, Oberley L W, Oberley T D, Loven D P 1984
Lowered superoxide dismutase activity in distant organs of tumor-bearing mice. Journal of the National Cancer Institute 72: 1065-1074.

Tubaro E, Lotti B, Cavallo G, Croce C, Borelli G 1980 Liver xanthine oxidase increase in mice in three pathological models. A possible defence mechanism. Biochemical Pharmacology 29: 1939-1943.

Tubaro E, Lotti B, Santiangeli C, Cavallo G 1980 Xanthine oxidase increase in polymorphonuclear leukocytes and macrophages in mice in three pathological situations. Biochemical Pharmacology 29: 1945-1948. 